\title{
Primary Care Physicians' Perceptions of the Effect of Insurance Status on Clinical Decision Making
}

\author{
David S. Meyers, $M D^{1}$ \\ Ranit Mishori, $M D^{1}$ \\ Jessica McCann, MA ${ }^{2}$ \\ Jose Delgado, $M D^{1}$ \\ Ann S. O'Malley, MD \\ Ed Fryer, $\mathrm{PbD}^{3}$
}

'Capital Area Primary Care Research Network (CAPRICORN), Georgetown University Medical Center, Washington, DC

${ }^{2}$ The Robert Graham Center Policy Studies in Family Medicine and Primary Care, Washington, DC

${ }^{3}$ Center for Child Health Research, University of Rochester School of Medicine, Rochester, NY

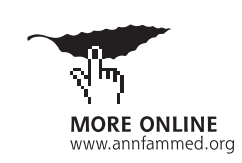

Conflicts of interest: none reported

\section{CORRESPONDING AUTHOR}

David Meyers, MD

Agency for Healthcare

Research and Quality

540 Gaither Rd

Rockville, MD 20850

dmeyers@ahrq.gov

\begin{abstract}
PURPOSE Americans who do not have health insurance receive fewer health services and have poorer health status than those who have insurance. To better understand this disparity, in this study we characterize primary care physician's perceptions of what effect, if any, patients' insurance status has on their clinical decision making during office visits.
\end{abstract}

METHODS Twenty-five physician members of CAPRICORN, a primary care practice-based research network in metropolitan Washington, DC, completed a brief paper-card survey instrument immediately after each patient encounter during 2 half-day office sessions. Participants saw patients in their usual manner and were given no additional information about their patients or their insurance.

RESULTS Eighty-eight percent of participating physicians reported making at least 1 change in clinical management as a result of a patient's insurance status. They reported altering their management during 99 of 409 patient encounters (24.2\%). There was a significant difference in the percentage of visits that involved a change in management for privately insured, publicly insured, and uninsured patients $(18.7 \%, 29.5 \%$, and $43.5 \%$ respectively, $P=.01)$. Physicians reported discussing insurance issues with patients during $62.6 \%$ of visits during which they made a change in management based on insurance status.

CONCLUSION Physicians incorporate their patients' insurance status into their clinical decision making and acknowledge they frequently alter their clinical management as a result. Additional research is needed to understand the effect of these changes on patient health and to assist both physicians and patients in enhancing the quality of care delivered within the constraints of the current insurance system.

Ann Fam Med 2006:4:399-402. DOI: 10.1370/afm.574.

\section{INTRODUCTION}

T thas long been recognized that Americans without health insurance, both children and adults, receive fewer health services and have lower

health status than those with insurance..$^{1-5}$ The underinsured and uninsured receive fewer preventive services, ${ }^{6-8}$ are more likely to be hospitalized for acute-care conditions, ${ }^{9}$ and are more likely to suffer adverse outcomes. ${ }^{10}$

Researchers have begun trying to tease out the mediating effects of clinicians on the use of health services and health outcomes for patients without insurance. Studies examining the effect of insurance status on physician immunization practices have found that despite believing in the merits of vaccines, physicians are less likely to administer them to children whose insurance did not cover them. ${ }^{11}$ In an anonymous national survey, almost 1 in 3 US physicians reported not offering useful services to patients because of coverage restrictions. Many doctors reported not discussing treatment options when they thought their patients' insurance would not cover them. ${ }^{12}$ 
Few studies to date have examined the role of insurance status in clinical decision making during the course of actual ambulatory care visits. ${ }^{13}$ As a result of a variation in members' opinions on the extent and appropriateness of incorporating insurance status into clinical decision making, the Capital Area Primary Care Research Network (CAPRICORN, http://www. capricorn.georgetown.edu) conducted a study to characterize clinicians' perspectives on what effect patient insurance status has on clinical decision making during office visits.

\section{METHODS}

Twenty-five members of CAPRICORN, a practice-based research network in the metropolitan Washington, DC, area, participated in this study (Table 1). Reflecting CAPRICORN's membership at the time, 12 were practicing at 1 of 4 sites affiliated with the Georgetown University Medical Center, 12 were practicing in nonprofit community health centers, and 1 physician practiced in a private group practice. These 25 physician participants represented $74 \%$ of CAPRICORN's members.

Participants completed a paper-card survey instrument immediately after each patient encounter during 2 self-selected half-day patient care sessions in September 2002. During the data collection period, physicians continued to see patients in their usual manner and were given no additional information about the patients or their insurance status other than what was contained in the patient's medical chart and billing slip. The study was overseen by the Georgetown University Institutional Review Board. Participants completed 409 paper cards after 411 visits, capturing $99.5 \%$ of visits. The main units of analysis for the study were the 409 physician-patient encounters.

\begin{tabular}{|lc|}
\hline \multicolumn{2}{|c|}{ Table 1. Characteristics of Participating Physicians } \\
\hline Characteristic & Number \\
\hline Specialty & \\
Family medicine & 23 \\
Pediatrics & 2 \\
Type of practice & \\
University-affiliated & 13 \\
Nonprofit health center & 11 \\
Private physician group & 1 \\
Sex & \\
Female & 13 \\
Male & 12 \\
Years in practice & \\
$0-3$ & 13 \\
$4-10$ & 7 \\
$>10$ & 5 \\
\hline
\end{tabular}

\section{Independent Variable}

The principle independent variable was patient insurance status. Each patient's insurance was coded into one of the following categories: private (private and Medicare + other), public (Medicare only, Medicaid, and other public), and uninsured.

\section{Dependent Variables}

The main dependent variable was whether the physician perceived that a patient's insurance or insurance status had any effect on his or her clinical decision making during the office visit. We referred to each physician's individual standard of care as their preferred management. Physicians recorded whether they altered their management strategy as a result of the patient's insurance status in a way they believed might negatively affect the patient. Physicians reported whether changes involved preventive services, diagnostic evaluations, and therapeutic treatments.

Participants were also asked to record on a visual analog scale the degree to which insurance entered their clinical decision-making process, regardless of whether the consideration resulted in a change. Other dependent variables included whether respondents discussed insurance with patients while discussing clinical options and whether insurance affected the length of the visit.

\section{Analytic Strategy}

The analysis was primarily composed of descriptive statistics and measures of association. A $\chi^{2}$ test was used to determine the association of management changes to insurance type. We used $t$ tests and analyses of variance to assess the degree to which insurance was considered during clinical decision making (as measured on a visual analog scale) with patient's sex, ethnicity, race, age-group, insurance type, and physician office type. We used a multivariate procedure to analyze the variance in the degree to which insurance was considered during clinical decision making accounted for by each and all of the predictor variables. In this analysis of covariance, age was not modeled as a categorical variable because of its linear relationship with the dependent variable found during bivariate testing. We decided a priori to use all 6 independent variables as predictors in the multivariate procedure. Only patient sex did not exhibit a significant association in bivariate tests. SUDAAN software (SUDAAN 9, Research Triangle Institute, Research Triangle Park, NC) was used to determine that the cluster design effect of intraphysician correlation had no effect on the relationship of insurance type to the dependent variable. 


\begin{tabular}{|c|c|c|}
\hline $\begin{array}{l}\text { Change in Preferred } \\
\text { Management }\end{array}$ & $\begin{array}{c}\text { Visits } \\
(\mathrm{n}=409) \\
\text { No. }(\%)\end{array}$ & $\begin{array}{c}\text { Visits With Discussion } \\
\text { of Insurance Issues } \\
\text { No. (\%) }\end{array}$ \\
\hline Any change & $99(24.2)$ & $62 / 99(62.6)^{*}$ \\
\hline Change in preventive service & $23(5.6)$ & $13 / 23(56.5)$ \\
\hline Change in diagnostic evaluation & $50(12.2)$ & $28 / 50(56.0)$ \\
\hline Change in therapeutic treatment & $65(15.9)$ & $46 / 65(70.8)$ \\
\hline None & $310(75.8)$ & $49 / 310(15.8)^{*}$ \\
\hline
\end{tabular}

\section{RESULTS}

Twenty-five physicians completed and returned 409 paper cards. Returned survey instruments averaged 16 per clinician with a range of 6 to 27. Fifty-eight percent of the patients seen were female, $44 \%$ were white, $44 \%$ were black, and $15 \%$ were Hispanic. Forty-nine percent of patients had private insurance, $15 \%$ had Medicaid, $3 \%$ had Medicare, 3\% had Medicare + other, 22\% had other public insurance, and 6\% were uninsured (Supplemental Table 1, available online only at http://www.

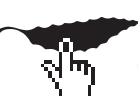

annfammed.org/cgi/content/full/4/5/399/DC1). All

91 patients classified as having "other public insurance" were covered by DC Health Alliance, a citysponsored insurance program for low-income residents.

Twenty-two of the 25 participating physicians (88\%) reported making a change from their preferred clinical management at least once. The physicians reported considering their patients' insurance status during 193 of 409 encounters (47.2\%). During 99 of the 409 encounters $(24.2 \%)$, physicians reported they made a clinical management change because of insurance issues (Table 2).

Physicians reported that 109 of the 409 encounters (27.1\%) included a discussion about insurance issues, and they were significantly more likely to discuss insurance issues during a visit in which there was a change from preferred management $(62.6 \%$ vs $15.8 \%, P<.001)$ (Table 2).

Visits were most likely to involve a change from the physician's preferred management when the patient was uninsured and were least likely to involve a change when the patient had private insurance $(P=.012)$ (Table 3 ).

Physicians reported considering insurance most strongly during clinical decision making when the patient was uninsured (Supplemental Table 2, available

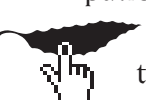
online only at http://www.annfammed.org/cgi/content/full/4/5/399/DC1). In multivariate analysis there were also significant associations between the degree to which physicians reported they considered insurance status while making clinical decisions and the indepen- dent variables of patient age and physician office type, but not patient race, ethnicity, or sex. Physicians reported giving less consideration to a patient's insurance status for children and more when they practiced in a community health center (Supplemental Table 3, available online only at http://www.annfammed. org/cgi/content/full/4/5/399/DC1).

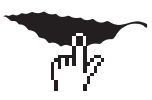

\section{DISCUSSION}

Physicians in this study recognized that they frequently alter their clinical management in response to patients' insurance status. While reviewing the findings with members of the network, study participants commented that some changes resulted in patient inconvenience, such as needing to take a medicine more times a day. They noted that prescribing 2 separate generic medicines instead of 1 brand-name combination pill or using a less-expensive but longer course of medication likely results in decreased adherence with medication regimens. Participants also reported changes that directly resulted in potential and actual negative effects on patients' health. Examples of these decisions included not prescribing medication to assist with smoking cessation and not referring a patient with a family history of colon cancer for colonoscopy.

Although physicians frequently consider patient insurance status and sometimes alter their preferred management as a result, this study does not link these changes with patient outcomes. We should not assume that every change from a physician's preferred management resulted in a lower quality of care. It is possible that insurance issues steered a physician toward an inexpensive thiazide diuretic for a patient with hypertension and away from a more-expensive and less-evidence-based medication preferred by the physician.

After controlling for insurance status, physicians who practice in community health centers reported

Table 3. Visits With a Change in Preferred Clinical Management by Insurance Type

\begin{tabular}{lcc}
\hline Patient Insurance & $\begin{array}{c}\text { Visits With } \\
\text { Change/Total Visits } \\
\text { No. }\end{array}$ & $\begin{array}{c}\text { Visits With } \\
\text { Change } \\
\%\end{array}$ \\
\hline Private & $40 / 208$ & 19.2 \\
Public & $49 / 170$ & 28.8 \\
Uninsured & $10 / 24$ & 41.6 \\
Not reported & $0 / 7$ & 0.0 \\
Total & $99 / 409$ & 24.2 \\
\hline$x^{2}=11.006, P=.012$ & & \\
\hline
\end{tabular}


considering insurance status to a degree greater than those who practiced in university-affiliated and private practices. This finding may reflect heightened sensitivity to cost issues among physicians who work with underserved patients in disadvantaged communities. Almost all physicians who participated found that they do consider insurance status at times, and although they reported considering insurance to a greater degree when a patient was uninsured, in almost $20 \%$ of visits involving patients with private insurance, they reported making a change from their preferred management.

This pilot study took advantage of the structure of the practice-based research network by involving a sizable number of practicing primary care clinicians for a short period to answer a question by examining realtime clinical practice. The high level of participation (with $99.5 \%$ of potential visits captured) reflects the buy-in of the network members and that the study was designed with clinician input to ensure its feasibility in the midst of active practice. Sharing the results with the member clinicians has generated a considerable amount of dialogue and increased the reflective nature of many physicians' practices.

This pilot study reflects some of the weaknesses of this new network. The results are based on a relatively small sample of physicians and patients and may not be generalizable, particularly in communities that are quite different demographically. The participants included a high percentage of clinicians providing health care services to an urban low-income population. In 2002, $15.3 \%$ of DC nonelderly residents were uninsured compared with $17.5 \%$ nationally, and $21.2 \%$ received public insurance compared with $14.6 \%$ nationally. ${ }^{14}$ In addition, the sample size might not have provided adequate power to detect differences among ethnic groups, and physician self-report might not capture all of the changes made by physicians.

Practicing primary care physicians incorporate their patients' health insurance status into their clinical decision making during office visits. They do so frequently, reporting in this study that they think about the patient's insurance status in almost one half of their encounters and alter their management in almost one quarter of all visits. Additional research is needed to understand the effect of these changes on patient health and to assist both doctors and patients in enhancing the quality of care delivered within the constraints of the current insurance system.

To read or post commentaries in response to this article, see it online at http://www.annfammed.org/cgi/content/full/4/5/399.
Key words: Health insurance; decision making; primary health care; practice-based research network

Submitted June 28, 2005; submitted, revised, February 23, 2005; accepted February 27, 2006.

Preliminary data from this study were presented as a poster at the North American Primary Care Research Group Meeting in November 2002.

Acknowledgments: The authors wish to acknowledge the enormous contribution of the study coordinator, Jennifer Doherty, the analytic advice of Professor Susan Dovey, and the dedicated work of all of CAPRICORN's member clinicians who are committed to improving health and health care.

\section{References}

1. Bloom B, Simpson G, Cohen RA, Parsons PE. Access to health care. Part 2: Working-age adults. Vital Health Stat 10. 1997:1-47.

2. Cohen RA, Bloom B, Simpson G, Parsons PE. Access to health care. Part 3: Older adults. Vital Health Stat 10. 1997:1-32.

3. Simpson G, Bloom B, Cohen RA, Parsons PE. Access to health care. Part 1: Children. Vital Health Stat 10. 1997:1-46.

4. Wood PR, Smith LA, Romero D, et al. Relationships between welfare status, health insurance status, and health and medical care among children with asthma. Am J Public Health. 2002;92:1446-1452.

5. Newacheck PW, Stoddard JJ, Hughes DC, Pearl M. Health insurance and access to primary care for children. N Engl J Med. 1998;338:513-519.

6. Arnold PJ, Schlenker TL. The impact of health care financing on childhood immunization practices. Am J Dis Child. 1992;146:728-732.

7. Coleman EA, Feuer EJ. Breast cancer screening among women from 65 to 74 years of age in 1987-88 and 1991. NCl Breast Cancer Screening Consortium. Ann Intern Med. 1992;117:961-966.

8. DeVoe JE, Fryer GE, Phillips R, Green L. Receipt of preventive care among adults: insurance status and usual source of care. Am J Public Health. 2003;93:786-791

9. Weissman JS, Gatsonis C, Epstein AM. Rates of avoidable hospitalization by insurance status in Massachusetts and Maryland. JAMA. 1992;268:2388-2394.

10. Weissman JS, Stern R, Fielding SL, Epstein AM. Delayed access to health care: risk factors, reasons, and consequences. Ann Intern Med. 1991;114:325-331.

11. Davis MM, Ndiaye SM, Freed GL, Kim CS, Clark SJ. Influence of insurance status and vaccine cost on physicians' administration of pneumococcal conjugate vaccine. Pediatrics. 2003;112:521-526.

12. Wynia MK, VanGeest JB, Cummins DS, Wilson IB. Do physicians not offer useful services because of coverage restrictions? Health Aff (Millwood). 2003;22:190-197.

13. Mort EA, Edwards JN, Emmons DW, Convery K, Blumenthal D. Physician response to patient insurance status in ambulatory care clinical decision-making. Implications for quality of care. Med Care. 1996;34:783-797.

14. Henry J Kaiser Family Foundation Kaiser Commission on Medicaid and the Uninsured. Health Insurance Coverage in America: 2003 Data Update. 2004. Available at: www.kff.org/uninsured/loader. $\mathrm{cfm}$ ?url=/commonspot/security/getfile.cfmspagelD $=49550$. Accessed: 17 December 2005. 